\title{
Changes in Health Consciousness of Nursing Students in Japan after Acquiring Medical Care Knowledge from a Nursing School
}

\author{
Yuriko Inoue ${ }^{*}$, Hiromitsu Ezure ${ }^{1}$, Junji Ito ${ }^{2}$, Chika Sawa1, Masato Yamamoto ${ }^{3}$, \\ Mone Hatasa Wakatsuki4, Harumi Hata5, Akiko Sasaki6, Masaaki Takayanagi7, \\ Takashi Takaki , Mikako Tanaka9 , Hiroshi Moriyama1, Naruhito Otsuka ${ }^{1}$ \\ ${ }^{1}$ Department of Anatomy, School of Medicine, Showa University, Tokyo, Japan \\ ${ }^{2}$ Department of Nursing, School of Nursing and Rehabilitation Sciences, Showa University, Tokyo, Japan \\ ${ }^{3}$ Department of Chemistry, Faculty of Arts and Sciences at Fujiyoshida, Showa University, Tokyo, Japan \\ ${ }^{4}$ Department of Perioperative Medicine, Division of Anesthesiology, School of Dentistry, Showa University, Tokyo, Japan \\ ${ }^{5}$ Center for Research and Development in Pharmacy Education, School of Pharmacy, Nihon University, Chiba, Japan \\ ${ }^{6}$ Department of Pharmacology, School of Medicine, Showa University, Tokyo, Japan \\ ${ }^{7}$ Saitama Prefectural University, Saitama, Japan \\ ${ }^{8}$ Division of Electron Microscopy, Showa University, Tokyo, Japan \\ ${ }^{9}$ Department of Chemical Engineering Science, Yokohama National University, Yokohama Japan \\ Email: ${ }^{*}$ inoue1978@med.showa-u.ac.jp
}

How to cite this paper: Inoue, Y., Ezure, H., Ito, J., Sawa, C, Yamamoto, M., Wakatsuki, M.H., Hata, H., Sasaki, A., Takayanagi, M., Takaki, T., Tanaka, M., Moriyama, $\mathrm{H}$. and Otsuka, N. (2021) Changes in Health Consciousness of Nursing Students in Japan after Acquiring Medical Care Knowledge from a Nursing School. Open Journal of Nursing, 11, 794-800. https://doi.org/10.4236/ojn.2021.119066

Received: July 9, 2021

Accepted: September 21, 2021

Published: September 24, 2021

Copyright $\odot 2021$ by author(s) and Scientific Research Publishing Inc. This work is licensed under the Creative Commons Attribution International License (CC BY 4.0).

http://creativecommons.org/licenses/by/4.0/

\begin{abstract}
Background: Health consciousness in daily life is very important because lifestyle habits, such as dietary and exercise habits, sleep, and smoking, are involved in the development and progression of lifestyle-related diseases, such as cancer, heart diseases, stroke, liver diseases, kidney diseases, and diabetes. Purpose: In this study, we surveyed to see if the health consciousness increased and what behaviors in daily life changed in students of a nursing school (Seiwa Nursing College, Tokyo, Japan) after they learned medical care knowledge required to become a nurse. Results: After learning medical care knowledge for 3 years, the students were found to have a higher level of health consciousness in the third year than they did in the first year. They applied the medical care knowledge they learned in daily life. All data were collected in 2019. Conclusions: The medical care knowledge learned in a nursing school was demonstrated to serve as information to increase the health consciousness.
\end{abstract}

\section{Keywords}

Health Consciousness, Nursing Students 


\section{Introduction}

In the Japanese population, the mortality from cancer is the highest, while the average life expectancy has increased to over 80 years for both men and women [1]. Health consciousness in daily life is very important because lifestyle habits, such as dietary and exercise habits, sleep, and smoking, are involved in the development and progression of lifestyle-related diseases, such as cancer, heart diseases, stroke, liver diseases, kidney diseases, and diabetes [2].

Students of a nursing school can work as a nurse in a healthcare setting only after they have acquired the necessary knowledge for a nurse, such as basic medicine and clinical medicine, from a nursing school in 3 years after enrollment and then passed the national examination for nurses [3] [4] [5] [6].

With the Covid-19 infection in the world, it is necessary to raise health consciousness. In Japan, there is not much education on health consciousness in public education. In Japan, the current situation is that there is not much education in general education to raise health consciousness. In Japan, health consciousness is still not as high as it is in the rest of the world [7] [8] [9]. To investigate whether various medical care knowledge acquired through learning for 3 years has any effect on the health consciousness of nurses themselves, we conducted a survey on students at a nursing school (Seiwa Nursing College, Adachi-Ku, Tokyo, Japan) to see if their health consciousness changed after they enrolled in the nursing school and to assess their acquired medical care knowledge compared with that before enrollment.

\section{Methods}

\subsection{Data Collection}

First- to third-year nursing students (194 people) were asked to answer the following question (2.2 Question) at nursing school (Seiwa Nursing College, Tokyo, Japan). The percentage of A and B answers to the nursing students' questions was calculated. The First-year nursing students are 75 people in the nursing school. The First-year women are 69 people and men are 6 people. The second-year nursing students are 64 people. The second-year women are 52 people and men are 12 people. Third-year nursing students are 52 people. The Third-year women are 45 people and men are 7 people.

There are 76 teenage women and 5 teenage men in the nursing school. The question-answer is A and B. There are 70 women and 13 men in their 20 s, and there are 15 women and 5 men in their 30s. There are teenage women and 5 teenage men in the nursing school. When the answer was B, the students were requested to describe specific changes in consciousness (Figure 1). All data were collected in 2019. We investigated if there were sex differences in health consciousness changes among the first-, second-, and third-year students after enrollment (Figure 2(a) and Figure 2(b)). We also investigated the changes in health consciousness of nursing students in different age groups (Figure 3(a) and Figure 3(b)). 


\subsection{Question}

Did you experience any changes in consciousness about your health or the health of your family or people around you after enrollment in nursing school and learning medical care?

Question:

Did you experience any changes in consciousness about your own health or the health of your family or people around you after enrollment in the nursing school and learning medical care?

\begin{tabular}{|l|c|}
\hline & People Composition ratio \\
\hline $\begin{array}{l}\text { A No, I did not experience any changes in health consciousness after } \\
\text { enrollment in the nursing school compared with that before the enrollment. }\end{array}$ & 84 (people) \\
\hline $\begin{array}{l}\text { B Yes, I experienced changes in health consciousness after enrollment in } \\
\text { the nursing school compared with that before the enrollment. }\end{array}$ & 110 (people) \\
\hline & Total 194(people) $100 \%$ \\
\hline
\end{tabular}

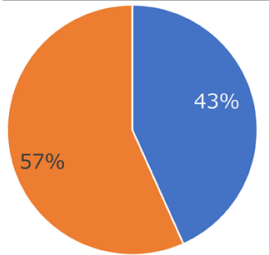

Figure 1. Changes in health consciousness of nursing students.

We investigated if there were sex differences in health consciousness changes among the first-, second-, and third-year students after enrollment

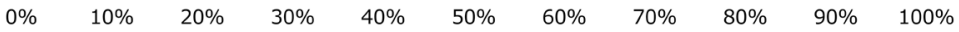

1st grade _ Women
1st grade _ Men
2nd grade _ Women
2nd grade _ Men
3rd grade _ Women
3rd grade _ Men

A There is no change in health consciousness before and after entering nursing school

B There is change in health consciousness before and after entering nursing school

(a)

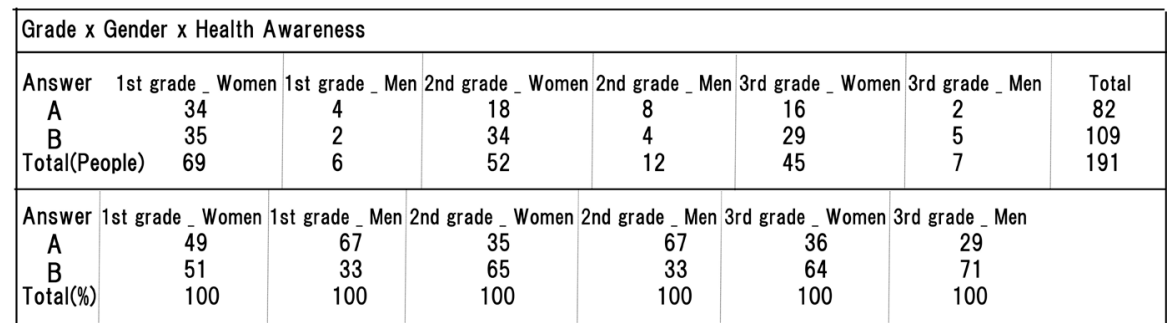

(b)

Figure 2. Changes in health consciousness of nursing students between men and women in each grade. 
We also investigated the changes in health consciousness of nursing students in different age groups

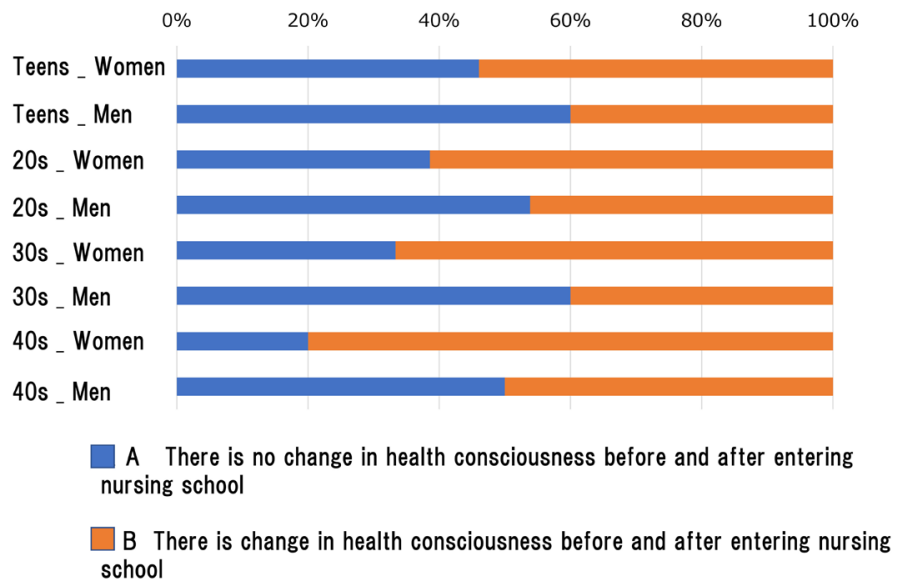

(a)

\begin{tabular}{|c|c|c|c|c|c|c|c|c|}
\hline \multicolumn{9}{|c|}{ Age $x$ gender $x$ health consciousness } \\
\hline $\begin{array}{c}\text { Answer } \\
\text { A } \\
\text { B }\end{array}$ & $\begin{array}{c}\text { Teens_Women } \\
35 \\
41\end{array}$ & $\begin{array}{c}\text { Teens_Men } \\
3 \\
2 \\
\end{array}$ & $\begin{array}{c}20 \text { s _ Women } \\
27 \\
43 \\
\end{array}$ & $\begin{array}{c}20 s_{-} \text {Men } \\
7 \\
6 \\
\end{array}$ & $\begin{array}{c}30 \text { s_ Women } \\
5 \\
10 \\
\end{array}$ & $\begin{array}{c}30 \text { s _ Men } \\
3 \\
2 \\
\end{array}$ & $\begin{array}{c}40 \text { s _ Women } \\
11 \\
4\end{array}$ & $\begin{array}{c}40 s_{\text {_ Men }} \\
1 \\
1\end{array}$ \\
\hline Total (people & 76 & 5 & 70 & 13 & 15 & 5 & 15 & 2 \\
\hline
\end{tabular}

\begin{tabular}{|cc|c|c|c|c|c|c|c|}
\hline Answer & Teens _ Women Teens _ Men & 20s _ Women & 20s _ Men & 30s _ Women & 30s_ Men & 40s _ Women & 40s _ Men \\
\hline A & 46 & 60 & 39 & 54 & 33 & 60 & 20 & 50 \\
B & 54 & 40 & 61 & 46 & 67 & 40 & 80 & 50 \\
\hline Total (\%) & 100 & 100 & 100 & 100 & 100 & 100 & 100 & 100 \\
\hline
\end{tabular}

(b)

Figure 3. Changes in health consciousness of nursing students in different age groups.

\section{A}

No, I did not experience any changes in health consciousness after enrollment in the nursing school compared with that before the enrollment.

B

Yes, I experienced changes in health consciousness after enrollment in the nursing school compared with that before the enrollment.

If your answer was B ("Yes, I experienced changes"), please describe the reason or the consciousness changes you experienced in detail based on your convenience.

\section{Results}

\subsection{Results Regarding Changes in Health Consciousness of Nursing Students}

Responses were obtained from all 194 first- to third-year students. Among them, more than half (57\%) answered that they experienced changes in their health consciousness after enrollment (Figure 1). The result suggests that the health consciousness of students themselves changed while after they enrolled in a 
nursing school and acquired medical care knowledge to work as a nurse in the future.

\subsection{Differences in Health Consciousness Changes between Men and Women in Each Grade}

We investigated if there were sex differences in health consciousness changes among the first-, second-, and third-year students after enrollment (Figure 2(a) and Figure 2(b)). There were 6 men and 69 women in the first year, 12 men and 52 women in the second year, and seven men and 45 women in the third year. It should be noted that the number of female students was higher than that of male students for all grades in the schools surveyed.

In both men and women, changes in health consciousness were more common among the third-year students than among the first-year students. Moreover, more than half of the female students in each grade experienced changes in health consciousness after enrollment (first-year female students: $51 \%$, secondyear female students: 65\%, and third-year female students: $64 \%$ ).

Among men, the third-year students were more health-conscious than firstor second-year students (third-year male students: 71\%).

\subsection{Changes in Health Consciousness of Nursing Students in Different Age Groups}

Students of a wide range of ages are enrolled in nursing school (in their 10s to 40s). There were 5 and 76, 13 and 70, 5 and 15, 2 and 5 men and women, respectively, in their 10s, 20s, 30s, and 40s, respectively (Figure 2 and Figure 3). The number of women was higher than that of men for all age groups. Women in all age groups were more health-conscious. Moreover, women in a more advanced age group were more health-conscious (female students in their 10s: 54\%, 20s: 61\%, 30s: 67\%, and 40s: 80\%) (Figure 3(a) and Figure 3(b)).

In men, the number of those who were health conscious was equal to that of those who were not for all age groups, indicating that the health consciousness in male students was not very high.

\subsection{Specific Changes in the Health Consciousness of Nursing Students}

We investigated specific changes in the health consciousness of nursing students. Students who experienced consciousness changes were requested to describe the particular changes.

Among the first-year students who experienced changes in health consciousness, the most common specific behaviors were incorporating infection prophylaxis measures, such as hand washing and exercising on a regular basis (7 students each). Other behaviors included modifications in dietary habits, such as salt reduction, exercising on a regular basis, and cessation of smoking. Some students reported that they became conscious about not only their physical health but also their families' physical health. Among the second-year students, 
the most common change in consciousness was exercising on a regular basis (17 students). The number of second-year students who were conscious about not only their physical health but also their families' physical health was higher than that of the first-year students. Many third-year students reported reviewing health checkup data, such as blood tests and blood pressure results, for assessing their physical health. The most common change in consciousness in third-year students was to exercise on a regular basis (12 students), as was the case in the second-year students.

The above results suggest that the third-year students were more healthconscious because of their deepened medical care knowledge. Nursing students tended to be more health-conscious when they spent more years in nursing school learning about medicine. Moreover, women in a more advanced age group were more health-conscious. Various medical care knowledge acquired through learning for 3 years affects the health-conscious of nurses themselves. The knowledge they have gained has increased their health-conscious.

\section{Discussion}

These findings suggest that nursing students become more conscious about their health as they gain more specialized knowledge in medicine after enrollment in a nursing school. These findings also suggest that health consciousness was shown to improve with increased medical knowledge. In our daily lives, health consciousness will increase life expectancy from day to day, but without understanding, it is difficult. We can get the necessary information for our health from school life and from various media in our daily lives. [10] We get the results that women in a more advanced age group were more health-conscious. These results suggest that women are more health-conscious than men because of the significant lifestyle changes women during menstruation, childbirth, and menopause [11]. With the Covid-19 infection in the world, it is necessary to raise health consciousness. [12] Nursing students and the general public have increased their medical knowledge compared to the past, suggesting that the covid-19 infection in the world is spreading. [12] As this survey was conducted on only one nursing school in Japan, there are limitations to the study. We need to accumulate data every year. It will be necessary to survey other nursing schools for the same question.

We also need to accumulate data every year. It will be necessary to survey other nursing schools for the same question. The findings also suggest that nursing students use the acquired medical care knowledge to increase health consciousness.

\section{Conclusion}

Immediately after enrollment in a nursing school, male students were less healthconscious than female students. However, male students, as well as female students, became more health-conscious as they advanced to the next year. The lev- 
el of health consciousness among the following students varied depending on their age; students in a more advanced age group were more health-conscious.

\section{Conflicts of Interest}

The authors declare no conflicts of interest regarding the publication of this paper.

\section{References}

[1] Tsugane, S. (2021) Why Has Japan Become the World's Most Long-Lived Country: Insights from a Food and Nutrition Perspective. European Journal of Clinical $\mathrm{Nu}$ trition, 75, 921-938. https://doi.org/10.1038/s41430-020-0677-5

[2] Koba, S., Tanaka, H., Maruyama, C., Tada, N., Birou, S., Teramoto, T. and Sasaki, J. (2011) Physical Activity in the Japan Population: Association with Blood Lipid Levels and Effects in Reducing Cardiovascular and All-Cause Mortality. Journal of Atherosclerosis and Thrombosis, 18, 833-845. https://doi.org/10.5551/jat.8094

[3] Kubosawa, S., Rajaonarison, N., Kitajima, M., Noto, Y. and Yamabe, H. (2012) Attitude Survey of Nursing Students in Madagascar and Japan. Open Journal of Nursing, 2, 4 p.

[4] Yoshioka, E. and Kaneko, S. (2019) The Acquisition of Ethical Competence in Basic Education and the Present State of Ethics Education. Open Journal of Nursing, 9, 676-686. https://doi.org/10.4236/ojn.2019.97052

[5] Yoshioka, E. and Kaneko, S. (2020) Examination of a Benchmark for Ethical Care Competence in Basic Nursing Education. Open Journal of Nursing, 10, 636-645. https://doi.org/10.4236/ojn.2020.106044

[6] Nakayama, A. and Sawada, Y. (2013) A Study on Nursing Student Communication Exercises in Mental Nursing Support Theory. Bulletin of Niimi Public University, 34, 75-78.

[7] Yuasa, M., Hoshi, T., Hasegawa, T., Nakayama, N., Takahashi, T., Kurimori, S. and Sakurai, N. (2012) Causal Relationships between Physical, Mental and Social Health-Related Factors among the Japanese Elderly: A Chronological Study. Health, 4, 133-142. https://doi.org/10.4236/health.2012.43021

[8] Shirasawa, T., Ochiai, H., Ohtsu, T., Nishimura, R., Shimizu, T., Hoshino, H., Tajima, N. and Kokaze, A. (2012) Parental Perceptions and Childhood Overweight/ Obesity: A Population-Based Study among School Children in Japan. Health, 4, 506-513. https://doi.org/10.4236/health.2012.48081

[9] Toyama, N., Kurihara, K., Muranaka, M. and Kamibeppu, K. (2013) Factors Influencing Self-Efficacy in Breastfeeding Support among Public Health Nurses in Japan. Health, 5, 2051-2058. https://doi.org/10.4236/health.2013.512278

[10] Awofeso, N., Gaber, Y. and Bamidele, M. (2019) Determinants of Youth Engagement with Health Information on Social Media Platforms in United Arab Emirates. Health, 11, 249-262. https://doi.org/10.4236/health.2019.112022

[11] Stefano, A., Radicioni, M., Vele, A., Eberhardt, A., Caccia, G., Focanti, F. and Salvatori, E. (2014) Tolerability and Hydrating Effects of an Anti-Aging Gynaecological Collagen Cream in Women in Menopause. Open Journal of Obstetrics and Gynecology, 4, 130-138. https://doi.org/10.4236/ojog.2014.43023

[12] Besteiro, B., Coutinho, D., Gomes, F., Almeida, M. and Almeida, J. (2021) Review of the Prognosis Factors of Covid-19 Infection. Advances in Infectious Diseases, 11, 196-215. https://doi.org/10.4236/aid.2021.112019 